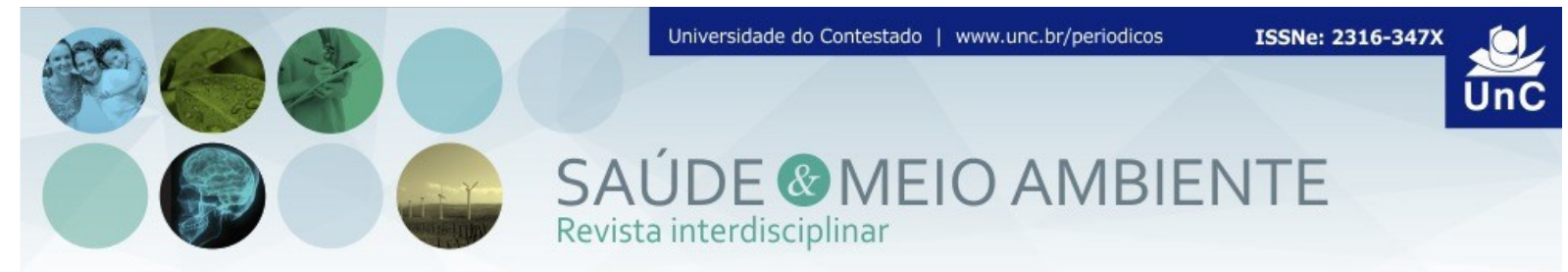

\title{
A COMUNICAÇÃO DOS RISCOS NA LOGÍSTICA REVERSA DAS EMBALAGENS DE AGROTÓXICOS NO BRASIL
}

Daniela de Ulysséa Leal ${ }^{1}$ Ivonete da Silva Lopes ${ }^{2}$

\begin{abstract}
RESUMO
Este artigo investiga como o Instituto Nacional de Processamento de Embalagens Vazias, responsável pelo programa de recolhimento de embalagens de agrotóxicos, comunica os riscos que envolvem as práticas com produtos agroquímicos através do conteúdo do seu site. Desde 2002, a responsabilidade compartilhada nesta cadeia de logística reversa é obrigatória por lei. Com a ajuda do software Iramuteq foi realizada uma análise de conteúdo baseada na frequência das palavras, resultando numa estrutura de nuvem, e de similitude. Através destas análises pode-se apreender que o instituto lança mão de eufemismo para comunicar tais riscos, inclusive substituindo o termo agrotóxico por defensivo agrícola.
\end{abstract}

Palavras-chave: Comunicação de Risco. Agrotóxico. Logística Reversa.

\section{THE COMMUNICATION OF RISKS IN THE REVERSE LOGISTICS OF AGROCHEMICAL PACKAGING IN BRAZIL}

\section{ABSTRACT}

This article investigates how the National Institute of Empty Packaging Processing, responsible for the pesticide packaging collection program, communicates the risks involved in agrochemical practices through the content of its website. Since 2002, shared responsibility in this reverse logistics chain is required by law. With the help of the Iramuteq softwear, a content analysis was performed based on the frequency of the words, resulting in a cloud structure, and similarity. Through these analyzes it can be seen that the institute uses euphemism to communicate such risks, including replacing the term agrotoxic with agricultural defensive.

Keywords: Risk Communication. Agrotoxic. Reverse logistic.

\footnotetext{
${ }^{1}$ Graduada em Comunicação Social, MBA em Marketing Estratégico pela Universidade Federal do Tocantins (UFT), mestranda em Extensão Rural na Universidade Federal de Viçosa (UFV), bolsista Capes, Brasil. Universidade Federal de Viçosa (UFV). Viçosa, Minas Gerais, Brasil. E-mail: dulyleal@gmail.com

${ }^{2}$ Graduada em Comunicação Social/Jornalismo, mestre e doutora em Comunicação pela Universidade Federal Fluminense (UFF). Atua como docente na Universidade Federal de Viçosa (UFV) e na linha de pesquisa Cultura, Políticas Públicas e Comunicação do Programa de PósGraduação em Extensão Rural (PPGER/UFV). Universidade Federal de Viçosa (UFV). Viçosa, Minas Gerais, Brasil. E-mail: ivonetesilvalopes@gmail.com
} 


\section{INTRODUÇÃO}

O uso abusivo de agrotóxicos nas lavouras brasileiras tem afetado a saúde dos consumidores e trabalhadores rurais, que lidam diretamente com estes produtos. Segundo Beck (2010), a indústria agroquímica é uma das fontes de riscos da modernidade tardia, e estes riscos escapam à percepção da maioria da população, constituindo situações sociais de ameaça, especialmente nos países em desenvolvimento. No Brasil, entre 2012 e 2014, segundo o atlas "Geografia do Uso de Agrotóxicos no Brasil e Conexões com a União Europeia" (2017) foram utilizados 8,33 $\mathrm{Kg}$ de agrotóxico por hectare, indicando um alto índice de troca neste mercado. Para comunicar estes riscos à sociedade são necessários certos pressupostos, fugindo, assim, de fatores que possam limitar a compreensão e comprometer os atores afetados.

Segundo a Lei Federal 9.974/00, de 06 de junho de 2000, é responsabilidade dos usuários do agrotóxico a devolução das embalagens vazias aos comerciantes que, por sua vez, devem ser reencaminhadas aos fabricantes. O Instituto Nacional de Processamento de Embalagens Vazias (Inpev) é uma entidade sem fins lucrativos, criada por fabricantes de agrotóxicos com o objetivo de promover a correta destinação das embalagens vazias de seus produtos. Tem suas ações financiadas pelas cerca de 100 organizações associadas, entre empresas agroquímicas do Brasil e entidades representativas do setor, e seus custos incluem itens como infraestrutura do Instituto e algumas unidades de recebimento, atividades de logística, destinação final, comunicação e educação, assessoria jurídica, desenvolvimento tecnológico e projetos de sustentabilidade. Em 2016, 44.528 toneladas de embalagens foram recolhidas pelo Inpev (INPEV, 2016), o que segundo o instituto representa 94\% das embalagens, indicando, a grande quantidade de agrotóxico que tem sido usada sobre o ecossistema. No entanto, essas informações estão bastante distantes dos dados fornecidos pelo posto de recebimento da Associação dos Revendedores de Defensivos Agrícolas da microrregião de Viçosa (ARDREV), que estimou em menos de $10 \%$ as devoluções.

O Inpev atua como núcleo de inteligência do Sistema Campo Limpo (SCL), nome do programa brasileiro de logística reversa de embalagens vazias de agrotóxicos. O programa abrange todas as regiões do país, tendo como base o conceito de responsabilidade compartilhada entre agricultores, indústria fabricante, canais de distribuição e poder público. Para divulgar o SCL, o instituto mantém o site www.inpev.org.br onde disponibiliza informações sobre a instituição e sobre o programa $^{3}$, desta forma o instituto não centraliza apenas a parte operacional de toda a logística reversa das embalagens de agrotóxico, mas também incorpora o compromisso de conscientização que envolve este processo.

O presente trabalho se concentrou em analisar como este instituto comunica, por meio de seu site, os riscos que o agricultor se submete ao desempenhar seu papel na cadeia da logística reversa do produto agrotóxico, visando compreender como o

${ }^{3} \mathrm{O}$ Inpev dispõe também de página no Facebook (https://www.facebook.com/inpEV/?ref=br_rs,) com 177.570 seguidores. 
Inpev cumpre sua parte, numa interação notadamente mediada pela confiança. Como procedimento metodológico efetuou-se análise de conteúdo de todo o site do Inpev (www.inpev.org.br), com a ajuda do softwear IRaMuTeQ ${ }^{4}$, que realiza análise de conteúdo através de análises estatísticas.

\section{RISCO DO AGROTÓXICO E DAS EMBALAGENS USADAS}

A busca pelo crescimento econômico e produtividade tem afetado as bases da sociedade contemporânea desenvolvendo situações de risco em todo o planeta, criando então, um novo paradigma para a sociedade atual. Segundo Beck (2010, p. 24): "Como é possível que os riscos coproduzidos no processo tardio de modernização sejam evitados ou minimizados, de modo que não comprometam as fronteiras do que é (ecológica, medicinal, psicológica ou socialmente) aceitável?"

Estes riscos podem se apresentar à sociedade de muitas maneiras, podendo ser ecológicos, químicos, nucleares e genéticos (GUIVANT, 2016, p. 95). Assim, dos novos produtos da indústria farmacêutica à super coxa de frango frita, do corante industrializado ao agrotóxico usado na zona rural e foco deste estudo, uma variedade de situações pode conter um risco silencioso. Este risco pode ser entendido como um perigo associado a um componente decisório, o perigo inerente a algo que se decide enfrentar, uma probabilidade silenciosa que tem seu alcance expandido pela globalização, afetando ser humano, fauna e flora (BECK, 2010).

O uso indiscriminado de produtos agroquímicos nas lavouras representa um grande ameaça para o meio rural, assim como para a sociedade em geral, que consome estes produtos ou faz uso da água que passa por propriedades contaminadas. Com a globalização destes riscos, estes podem também afetar diretamente aqueles que os produzem ou se beneficiam destes, o que Beck (2010) denomina de "Efeito Boomerang".

Por aliar elementos reais, como os danos já ocorridos, e potenciais, como perigos calculados, o risco atravessa diversas dimensões. Ao se admitir a força e a onipresença do risco, tratando-o como normalidade, este passa a ser incorporado às rotinas. Segundo Ulrich Beck (2010), a presença do risco em uma sociedade desloca esta estrutura social para uma sociedade de risco, na qual a distribuição dos riscos não corresponde às diferenças sociais, econômicas e geográficas da típica da modernidade. A sociedade de risco é estratificada pelo conhecimento do próprio risco, ou seja, o poder está nas mãos de quem o conhece.

Os variáveis riscos apresentam características comuns entre si, como a produção industrial, portanto, frutos diretos ou indiretos da ação humana. Desta

\footnotetext{
${ }^{4}$ IRaMuTeQ (Interface de R pour les Analyses Multidimensionnelles de Textes et de Questionnaires) é um software livre ligado ao R para análise de dados textuais, desenvolvido pelo Laboratoire d'Études et de Recherches Appliquées en Sciences Sociales da Universidade de Toulouse. Por meio do seu ambiente $R$, o softwear oferece conjunto de tratamentos e ferramentas de análise estatística que apontam o posicionamento, a estruturação e as relações de palavras no texto.
} 
mesma forma geralmente são externalizados economicamente, cabendo aos indivíduos da sociedade de risco o ônus desta presença e de suas consequências. Além disso, os riscos são também individualizados juridicamente, reforçando, quase sempre, a dificuldade de se evidenciar as relações de causa e efeito (GUIVANT, 2016).

Os riscos também são legitimados cientificamente. Beck (2010) traz a luz questionamentos sobre estudos científicos acerca dos riscos da atualidade, por conterem muitas lacunas. Em primeiro lugar, podem ter alcance limitado, pois nem mesmo todas as substâncias podem ser avaliadas no seu potencial de risco, nem podem ser avaliados os efeitos das diversas combinações nos nossos corpos e no meio ambiente. Muitos estudos também não consideram efeitos cumulativos em longo prazo, muitos projetaram para os seres humanos, de uma forma errônea, resultados estudados em animais, ou deixaram de levar em conta fatores sociais que podem influenciar a sensibilidade particular de cada indivíduo, entre outras limitações.

Além destas características comuns, a mídia, financiada por corporações, tende a minimizar os riscos quando precisa reportá-los para a sociedade. Da mesma forma os riscos são negociados e, muitas vezes, mascarados politicamente. Por exemplo, dentre os 614 tipos de substâncias utilizadas na agricultura como agrotóxicos, divulgadas pela Agência Nacional de Vigilância Sanitária (Anvisa), apenas 97 são proibidos no país, considerando que os demais não apresentam risco agudo à saúde. Como risco agudo é entendido intoxicações que podem ocorrer dentro de um período de $24 \mathrm{~h}$ após a ingestão do produto. Segundo dossiê da Associação Brasileira de Saúde Coletiva (Abrasco), a intoxicação crônica por agrotóxicos pode causar efeitos neurotóxicos retardados, alterações cromossomiais, dermatites de contato, lesões hepáticas, arritmias cardíacas, lesões renais, neuropatias periféricas, alergias respiratórias, dermatites, doença de Parkinson, cânceres, entre outros (CARNEIRO, 2015).

O termo agrotóxico no Brasil passou a ser utilizado para denominar os venenos agrícolas, colocando em evidência a toxicidade desses produtos ao meio ambiente e à saúde humana. O termo é definido pela Lei Federal $n^{\circ} 7.802$ de 11 de julho de 1989 , regulamentada pelo Decreto 98.816 e, posteriormente, pelo Decreto $n^{\circ} 4.074$, de 04 de janeiro de 2002. Apesar da toxidade, o Governo Federal tem legitimado o uso de agrotóxicos de diversas naturezas no meio rural, como ofertando pacotes tecnológicos através do Programa Nacional de Fortalecimento da Agricultura Familiar (Pronaf), orientado para o crédito vinculado a uma assistência técnica alinhada à modernização da agricultura familiar.

A segurança conquistada pelo amparo destas legislações, que já é frágil, pode tornar-se ainda mais vulnerável caso seja aprovado o projeto de lei (PL) 6.299 de 2002, de autoria do senador federal Blairo Maggi, já aprovado pela Comissão Especial da Câmara dos Deputados por 18 votos favoráveis e apenas nove contrários em 28 de junho de 2018. O projeto altera os artigos $3^{\circ}$ e $9^{\circ}$ da Lei $n^{\circ} 7.802$ que dispõe sobre os agrotóxicos, passando estes a ser regulados por seu princípio ativo, e também, exclui o Ministério da Saúde e o Ministério do Meio Ambiente do processo de registro desses produtos. A maior articuladora deste PL no Congresso, a deputada Tereza 
Cristina (DEM- MS), conhecida como a "Musa do Veneno" e presidente da Frente Parlamentar Agropecuária e Ministra da Agricultura no governo de Bolsonaro.

O próprio portal da Câmara dos Deputados ${ }^{5}$ se refere ao PL 6299 como um projeto que visa regular defensivos fitossanitários, e não agrotóxicos, como versa a lei ainda em vigor. Lança mão de eufemismo nesta ação de comunicação com a sociedade para dissimular o risco inerente ao produto, o que promove o desserviço da desinformação e compromete a saúde pública. O uso deste eufemismo irá dissimular o risco inerente ao produto, promovendo o desserviço da desinformação e comprometendo a saúde pública. Segundo Oliveira (2012, p. 122), o objetivo deste deslocamento semântico do termo agrotóxico para fitossanitário é promover a interpretação de que o agrotóxico é "um instrumento produtivo que não provoca problemas ao meio ambiente ou doenças no trabalhador desde que adequadamente manuseado", atribuindo ao manuseio do agricultor os males que possam ser causados ao ambiente ou à saúde, isentando a ação do produto e da indústria.

Esse projeto de lei vem sendo considerado pela Frente Parlamentar Ambientalista e por movimentos sociais como "Pacote do Veneno", além da mudança de nomenclatura agrotóxico inclui, ainda, projetos que afrouxam as normas para toda a cadeia. Revoga a atual lei do agrotóxico, restringindo a competência dos estados e municípios para legislar sobre o tema e flexibiliza a regulamentação da propaganda de agrotóxico. O Instituto de Meio Ambiente e Recursos Naturais Renováveis (Ibama) se posicionou contra este pacote, destacando o retrocesso que significa sua aprovação para o Brasil.

Dentre os agrotóxicos comercializados no Brasil, o glifosato, ingrediente ativo do Round $U p^{6}$, é o mais vendido no Brasil, o volume comercializado supera a soma de todos os outros agroquímicos. Pertencente à família de compostos organofosforados (OPs), é o herbicida mais amplamente utilizado no mundo hoje em dia, permitido em mais de 130 países. Foi historicamente usado como inseticida e como agentes químicos na Segunda Guerra Mundial, passando a ser utilizado como biocida na década de 1970, quando começou a ser identificado um significativo aumento no número de casos de intoxicação por OPs, mesmo em baixas doses (ARAÚJO et al., 2007). O contato humano com este herbicida de alta toxidade se dá pelo ar e pelo consumo de água potável contaminada (CARNEIRO, 2015).

Os inseticidas organoclorados, também introduzidos após a Segunda Guerra Mundial, foram amplamente utilizados na agricultura e na saúde. O dicloro-difeniltricloroetano (DDT) foi o precursor dos organoclorados, pois sua propriedade inseticida, aliada à baixa solubilidade em água, alta persistência e sua forma de ação, desconhecida até aquele momento, propiciou resultados inseticidas potentes, e seu se expandiu rapidamente (CARNEIRO, 2015). Segundo o "Panorama da Contaminação Ambiental por Agrotóxicos e Nitrato de Origem Agrícola no Brasil: Cenário 1992/2011" da Empresa Brasileira Meio Ambiente (Embrapa), são encontrados normalmente tanto no solo como nas águas subterrâneas da região

\footnotetext{
${ }^{5}$ Disponível em <http://www2.camara.leg.br/atividade-legislativa/comissoes/comissoes-

temporarias/especiais/55a-legislatura/pl-3200-15-regula-defensivos-fitossanitarios-1>. Acesso em: 08 ago. 2018.

${ }^{6}$ Roundup é o nome comercial de um herbicida fabricado pela Monsanto.
} 
Sudeste compostos organoclorados, como o DDT, resultantes das aplicações sucessivas na cafeicultura durante as décadas de 50, 60 e 70 do século passado (GOMES, 2014).

Os dados apresentados pela Embrapa demonstram que estes tipos de agrotóxicos produzem efeitos ao longo do tempo, podem sofrer transformações no período em que permanecem no meio ambiente, como alterações no nível bioquímico, tornando-se necessário o monitoramento de águas, solos, ar e alimentos. Quanto maior a quantidade dos agrotóxicos, menor a quantidade de microrganismos e menor será o poder de biodegradação, aumentando o tempo de persistência do agrotóxico no ambiente (CARNEIRO, 2015). Neste sentido, o Programa de Análises de Resíduos de Agrotóxicos em Alimentos (PARA), em 2011, coletou amostras em todos os estados do Brasil e segundo análise, um terço dos alimentos consumidos cotidianamente pelos brasileiros estava contaminado por agrotóxicos.

Os agrotóxicos também afetam o sangue dos doadores e receptores de transfusões, segundo recente estudo da Faculdade de Medicina da USP de Ribeirão Preto relatando, inclusive, danos genotóxicos decorrente da mistura de produtos agrotóxicos (NEVES, 2017). Este estudo destaca a falta de questionamentos sobre o uso destes produtos na hora da coleta de sangue. De acordo com Bombardi (2017), no Brasil são registrados 3.125 casos de intoxicação por agrotóxicos por ano, sendo que, para cada caso notificado, acontecem 50 sem notificações.

Não obstante aos males trazidos pelo uso excessivo de agrotóxico, o Ministério da Agricultura, Pecuária e Abastecimento (MAPA), em janeiro de 2017, aprovou o registro de 277 novos agrotóxicos, sendo 161 chamados genéricos. O número representa um crescimento de $374 \%$ comparado a 2015. Além disso, são apreendidos anualmente mais de 30 toneladas de agrotóxicos falsificados vindo do Paraguai. A pressão mercadológica sobre a agricultora desconsidera o princípio da precaução e oferta mais produtos que o necessário, fazendo, consequentemente, circularem mais embalagens, que também são fontes de toxidade.

Primeiramente, os riscos estão presentes nestas embalagens pela dificuldade de se compreender as informações inerentes ao produto, uma vez que é concebido e rotulado em laboratório e usa linguagem técnico-científica, o que potencializa o grau de perigo do seu uso. Estudos anteriores (PERES, 1999) já apresentaram resultados demonstrando que poucos usuários de agrotóxicos têm o conhecimento necessário para a manipulação destes produtos. Somente alguns costumam ler o receituário agronômico e compreender as informações contidas na bula dos produtos, considerando que tipos diferentes de agrotóxicos exigem diferentes precisões de uso para ofertar uma mínima margem de segurança para o usuário. Além disso, a relação entre o trabalhador rural e o produto se dá de forma muito próxima, pois este lida com o seu manuseio direto, muitas vezes sem fazer uso de Equipamento de Proteção Individual (EPI).

O processo de lidar com a embalagem pode apresentar perigos para a saúde inclusive na hora do seu descarte. Segundo a Lei Federal 9.974/00, de 6 de junho de 2000, posteriormente atualizada pelo Decreto 4.074, de 4 de janeiro de 2002, é responsabilidade dos usuários do agrotóxico a devolução das embalagens vazias aos 
comerciantes que, por sua vez, devem ser reencaminhadas aos fabricantes. O agricultor tem a tarefa de devolver a embalagem no prazo de um ano a contar da data da compra no local indicado na nota fiscal e o comerciante deve oferecer um local para esta devolução e indicá-lo na nota fiscal.

É atribuição do trabalhador rural realizar a tríplice lavagem das embalagens, que também devem ser perfuradas, e dos equipamentos de aplicação de agrotóxicos, que muitas vezes são lavados em água de múltiplo uso, o que pode vir a ser mais uma fonte da exposição humana aos venenos. Os resíduos de agrotóxicos nas embalagens que são descartadas no ambiente ou vão para aterros e lixões contaminam o solo e o subsolo quando são levados ao lençol freático pela ação da chuva. Da mesma forma, são poluentes do ar quando queimadas.

O conceito de responsabilidade compartilhada, conjunto de atribuições individualizadas e encadeadas, na destinação correta das embalagens vazias dos agrotóxicos visa identificar o papel de cada membro da cadeia, como os agricultores, distribuidores e cooperativas, indústria (representada pelo Inpev) e o poder público. Desta maneira, todos são responsáveis pela destinação das embalagens vazia por terem se beneficiado do produto.

Os postos de recebimento recebem as embalagens vazias e classificam entre lavadas e não lavadas, separam segundo o tipo de material e são responsáveis por emitir um comprovante de entrega para os agricultores. As centrais também realizam estas classificações e compactam as embalagens, cabendo ao fabricante do produto encaminhar as embalagens lavadas para reciclagem e incinerar as contaminadas. Porém, muitos são os obstáculos encontrados pelos agricultores para realizar esta devolução, desde a distância dos postos de recolhimento e horários restritos para este recebimento. Na Região da Zona da Mata Mineira, especificamente na microrregião de Viçosa ${ }^{7}$, o posto de recolhimento fica no município de Coimbra e o recolhimento está restrito apenas a dois dias na semana (segunda e terça), em horário comercial, situação que leva, não raramente, o agricultor a optar por permanecer com a embalagem. Muitas vezes, ao guardar esta embalagem, esta acaba sendo utilizada para armazenar alimentos ou outros pertences.

O Instituto Mineiro de Agropecuária $(\mathrm{IMA})^{8}$ já identificou situações em que as embalagens eram usadas como recipiente para armazenar água de beber, alimentos ou na pia para guardar o sabão de lavar louça. Algumas vezes foram cortadas para servir como vasos ou suporte de objetos e até mesmo embalagens grandes utilizadas como caixa de água. Estes exemplos são frutos de um entendimento precário sobre o risco existente nas embalagens, indicando que a comunicação neste sentido deve seguir pressupostos para não limitar o sentido das mensagens.

\footnotetext{
${ }^{7} \mathrm{~A}$ microrregião de Viçosa apresenta uma agricultura de porte intermediária, com destaque para a cultura cafeeira, segunda maior área produtora do Estado,

${ }^{8}$ Apresentação IMA exibida no Seminário sobre Impactos dos Agrotóxicos: Realidade, Governança e Estratégias Públicas de Ação, promovido pelo GEP/MG no auditório da Emater, Belo Horizonte em $17 / 04 / 2018$.
} 


\section{COMUNICAÇÃO DE RISCO}

Comunicar os riscos (CR) a que uma população está sujeita é um processo de caráter dinâmico, visto que a comunicação varia de acordo com o risco, com a população e com outras variáveis. A CR pode ser compreendida enquanto troca de informações e opiniões acerca do risco, considerando desde a elaboração de mensagens acerca da natureza do risco, bem como preocupações, opiniões e reações resultantes da divulgação das mensagens, e as questões legais que abordam o processo de gestão do risco (JESUS, 2016).

Para Furnival et al. (2004), apenas a transmissão de informações sobre o risco, mesmo em grande quantidade, não apresenta elementos suficientes para garantir uma comunicação eficaz sobre estes, fazendo-se necessárias "mudanças das metas, configurações e ações institucionais, culturais e sociais" para que a compreensão dos indivíduos seja plena e a comunicação dos riscos efetiva.

A CR representa, então, uma situação na qual a população tem acesso à informação e, da mesma forma, tem envolvimento com a prevenção do risco, configurando uma relação baseada na troca de percepções e opiniões de vários atores sociais, como instituições governamentais, empresas, comunidades, academia e meios de comunicação, entre outros, sobre o risco, sua natureza, impacto e controle (COVELLO, 1993). A linguagem deve ser então, adequada, reforçando a compreensão dos processos pelo público leigo.

Neste sentido, para que os riscos sejam realmente comunicados é preciso que haja um alinhamento entre a percepção do risco por parte do emissor e do receptor. Quando estes papéis são desempenhados por atores com valores socioeconômicos muito contrastantes este alinhamento torna-se mais difícil, geralmente prevalecendo a ótica do mais forte. Na opinião de Di Giulio et al. (2012) a abertura de diálogo e do processo decisório aumenta a confiança da população neste processo, legitimando0 .

Lofstedt (2012) destaca o papel da confiança na amplificação social do risco, fenômeno pelo qual à experiência social do risco é moldada pelos processos de informação, pelas estruturas institucionais, pelo comportamento do grupo social e pelas respostas individuais. A aceitação do risco dependente mais expressivamente da confiança do público em um gerenciamento eficaz do risco do que em estimativas quantitativas. Historicamente, a indústria e o Estado não têm trazido a sociedade para debates em relação a situações de riscos e de crise, não os integrando nas tomadas de decisões (COVELO, 1993).

Os modelos vigentes, nos quais a regulação dos riscos se baseia em dados quantitativos e avaliações técnico-científicas, negligenciando fatores sociais, culturais e econômicos, precisam dar espaço para debates no quais todos os atores, que direta ou indiretamente sejam afetados pelos riscos, tenham voz. Segundo Fischhoff (1995, p. 144), se a comunicação de risco for efetiva "pode cumprir parte do contrato social entre aqueles que criam os riscos (como um subproduto de outras atividades) e aqueles que os irão suportar (talvez juntamente com os benefícios dessas 
atividades)." Desta forma, numa sociedade estratificada pelo conhecimento dos riscos a que está submetida, a socialização desses debates pode se aproximar, analogamente, do ideal de justiça social.

\section{METODOLOGIA}

Como procedimento metodológico, este trabalho lançou mão da análise de conteúdo, procedimento sistemático para levantamento de indicadores que permitam a realização de inferência sobre determinado texto (BARDIN, 1977), de todo o site do Inpev, nos meses 11 e 12 de 2017. Estas análises de conteúdo foram realizadas com o auxílio do software IRaMuTeQ (Interface de $R$ pour les Analyses Multidimensionnelles de Textes et de Questionnaires), um software livre ligado ao $\mathrm{R}$ para análise de dados textuais, desenvolvido pelo Laboratoire d'Études et de Recherches Appliquées en Sciences Sociales da Universidade de Toulouse. Por meio do seu ambiente $R$, o software oferece conjunto de tratamentos e ferramentas de análise estatística que apontam o posicionamento, a estruturação e as relações de palavras no texto. As análises utilizadas foram nuvem de palavras, que a partir de um indicador de frequência, estrutura as palavras em forma de nuvem, relacionando os tamanhos com a importância no corpus textual e a análise de similitude, grafo que representa a ligação entre as palavras dentro de um corpus textual. As imagens presentes nas campanhas do Inpev serão investigadas através da análise semiótica, na qual se busca compreender os signos escolhido para comunicar, pois, segundo Pierce (1977) os signos representam diferentes perspectivas a partir do referencial de cada sujeito.

\section{RESULTADOS E DISCUSSÕES - A COMUNICAÇÃO DOS RISCOS DO AGROTÓXICO PELO INPEV}

Através da análise de conteúdo do site www.inpev.org.br foi obtido um corpus geral, separado em 147 segmentos de texto (ST), com emergência de 5392 ocorrências (palavras, formas ou vocábulos), sendo 1402 palavras distintas e $712 \mathrm{com}$ uma única ocorrência. Em seguida, foi analisada a nuvem de palavras estruturada pelo softwear (ver Figura 1), verificando-se que a palavras mais presentes em todo o site foi "embalagem", com 110 ocorrências, seguida por recebimento com 34 ocorrências, sinalizando que o foco da comunicação está mais voltado ao objeto do que ao risco que o envolve. Desta forma, esta comunicação se mostra de caráter utilitarista e instrumental, priorizando a mecânica e operacionalização do trato com a embalagem, em detrimento a outros aspectos mais afins a uma reflexão ambiental. 
Figura 1 - Nuvem de palavras com base no conteúdo do site INPEV

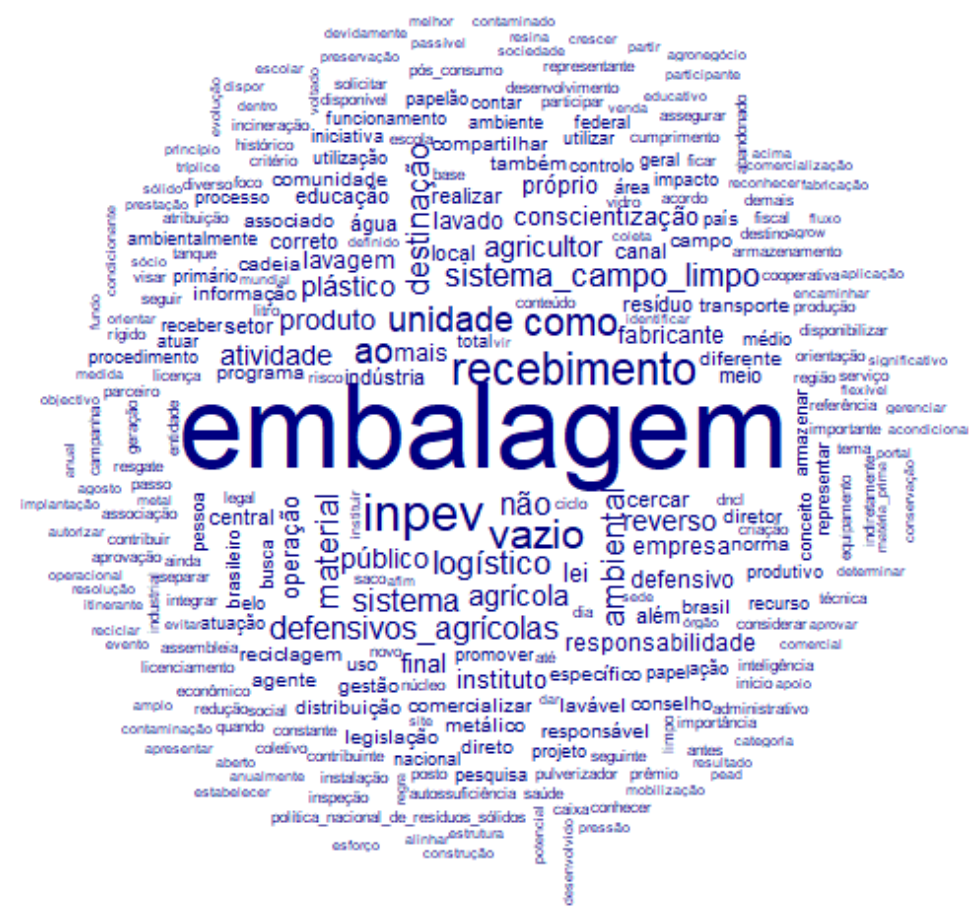

Fonte: Textos do www.inpev.org.br. Gráfico gerado pelo Iramuteq em 12/03/2018.

O nome Inpev aparece 40 vezes no site, frisando a identidade da instituição. Da mesma forma, o nome do programa, Sistema Campo Limpo, também tem ocorrência significativa, 22 vezes. As indústrias agroquímicas, através do Inpev, ocupam uma posição de privilégio nesta cadeia da logística reversa que tende a ser um campo $^{9}$ de disputas com jogadores de pesos desiguais, a começar pela discrepância do capital econômico. A promoção institucional tende a significar o Inpev como equiparado ao agricultor, ocultando esta diferença dimensional.

A locução "defensivo agrícola" apresenta 20 ocorrências e a palavra defensivo 13, sendo estas as únicas nomenclaturas usadas no site para se referir ao produto agrotóxico. Desta forma, o Inpev oculta do agricultor que se submete a compartilhar esta responsabilidade, a gama de riscos a que está exposto no momento do trato e do armazenamento das embalagens e produtos. Além disso, o Inpev dissemina uma falácia ao associar a ideia de "defesa" ao veneno, aliando aspectos subjetivos positivos a produtos que podem ser altamente nocivos.

A palavra conscientização aparece ao todo 14 vezes no conteúdo do site, sugerindo um paradoxo no qual o agente afetado pelo risco é estimulado a usar sua consciência, mas sustentada em bases fictícias, nas quais os conceitos são destorcidos para encobrir os riscos. Foram encontradas em menores ocorrências palavras como: água (11), resíduo (11), legislação (8), impacto (7), contaminação (6), parceiros (5), risco (5), preservação (3). Neste sentido, podemos perceber que o

\footnotetext{
${ }^{9}$ Segundo Bourdieu (2004), a posição do agente no campo, determinada pela composição total do seu capital, implica em maior ou menor dominação (ou subordinação) em relação aos demais agentes.
} 
propósito deste incentivo à prática de inserção nesta cadeia, não se dá pelo interesse em se despertar consciência ambiental (e consciência sobre a crise planetária acerca de recursos naturais) nos agricultores, visto que teria que envolver outras práticas próambientais diárias ou esporádicas, possibilitando que este sujeito rural esbarrasse em reflexões sobre os impactos do modo conservador de produção agrícola.

Figura 2 - Análise de similitude do conteúdo do site do Inpev.

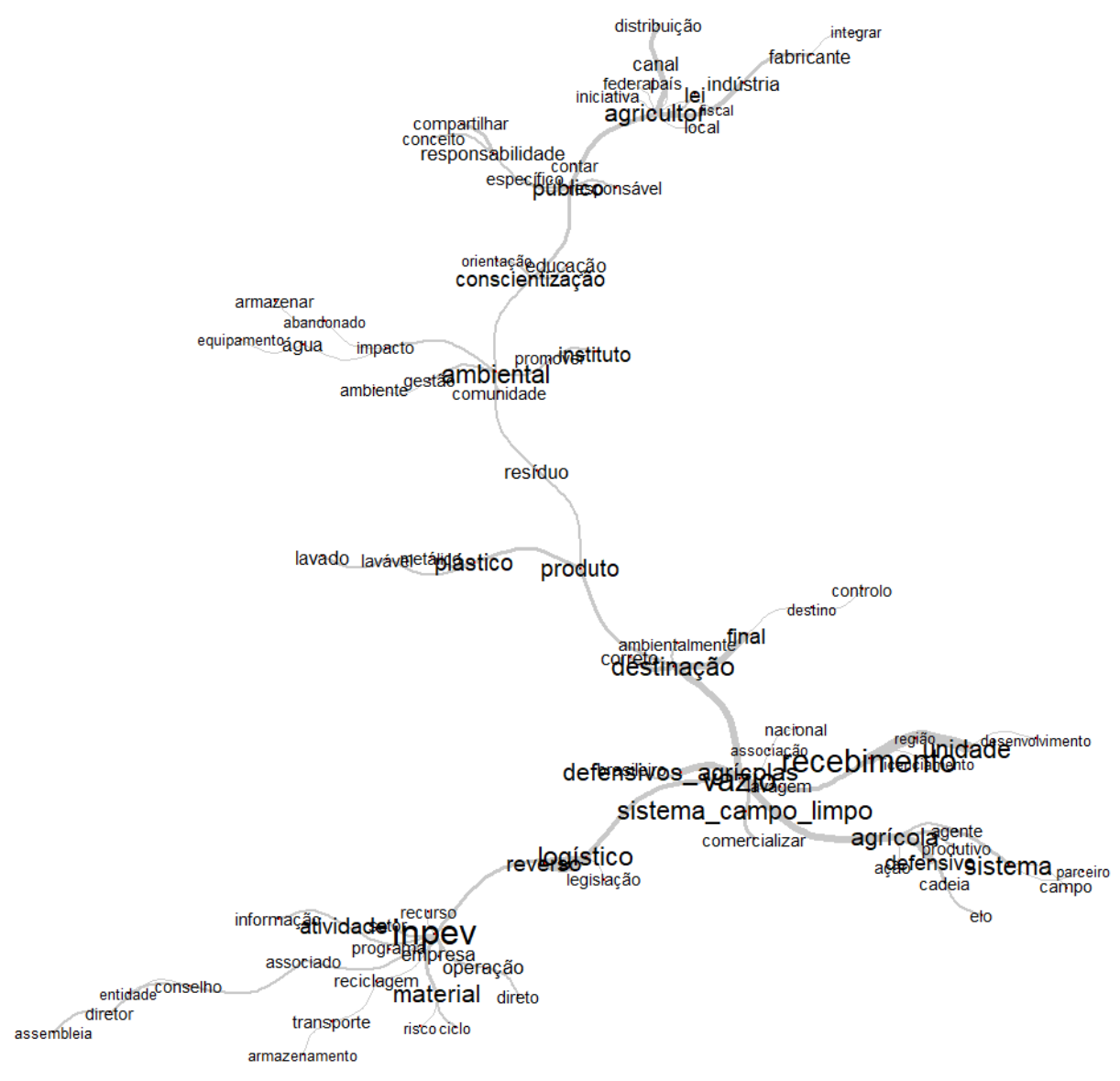

Fonte: Textos do www.inpev.org.br. Gráfico gerado pelo Iramuteq em 12/03/2018.

A partir da análise de similitude (Figura 2) baseada na teoria dos grafos é possível identificar as ocorrências entre as palavras e as indicações da conexidade entre elas, o que auxilia na identificação da estrutura do conteúdo do corpus textual, sendo possível inferir os temas de relativa importância abordados no discurso do Inpev. Para esta análise suprimimos a palavra embalagem (palavra mais recorrente) para obter um gráfico legível e menos poluído.

Observa-se que duas palavras apresentam maior força no conteúdo do site, "Inpev" e "recebimento", e apresentando um grau imediatamente inferior de força temos: "agricultor", "público", "conscientização", "ambiental”, "destinação", defensivo agrícola", "Sistema Campo Limpo". Desta maneira, percebe-se a intenção de fortalecimento 
institucional, reafirmando seu papel de recebedor de embalagens vazias. Por outro lado, com base nesta segunda categoria de palavras, pode-se perceber que o discurso relaciona o agricultor ao papel de agente pró-ambiental, de quem é demandada a consciência e a atitude de dar destino correto às embalagens vazias, sem que haja uma ruptura com o modelo produtivo. Segundo a lógica deste discurso, devolver as embalagens no lugar especificado ocupa uma posição tão significativa no escopo próambiental que o inocenta do veneno espalhado pelo ecossistema.

O termo defensivo agrícola, usado no lugar de "agrotóxico" pelo Inpev em seu discurso, aparece na Figura 2 próximo dos termos "lavagem", "associação", "agente", "produtivo", "parceiro", "campo". Nesse sentido, pode-se inferir que, além de estar associado à obrigatoriedade da lavagem por parte do agricultor, o termo "defensivo agrícola" remete à produtividade e parceria no campo. Não identificamos nesta análise associações entre o termo "defensivo agrícola" e os riscos à saúde e ao meio ambiente, ou relações com contaminação.

O Inpev lança mão, também, de estratégias de cunho visual para dissimular os riscos inerentes aos agrotóxicos em seu site (Figura 3). Ao retratar a monocultura, prática danosa ao solo, como modelo de agricultura, o Inpev reproduz, naturaliza e incentiva tal prática, que se caracteriza por tornar o solo empobrecido, mais sensível a pragas, além de diminuir sua produtividade, tornando-se necessária a aplicação de mais agroquímicos. A utilização de um "espantalho" sorridente está mais associada ao lúdico do que aos riscos que o agrotóxico oferece, deslocando a percepção destes riscos para uma atmosfera de progresso e serenidade.

Figura 3 - Campanha do Dia Nacional do Campo Limpo 2017

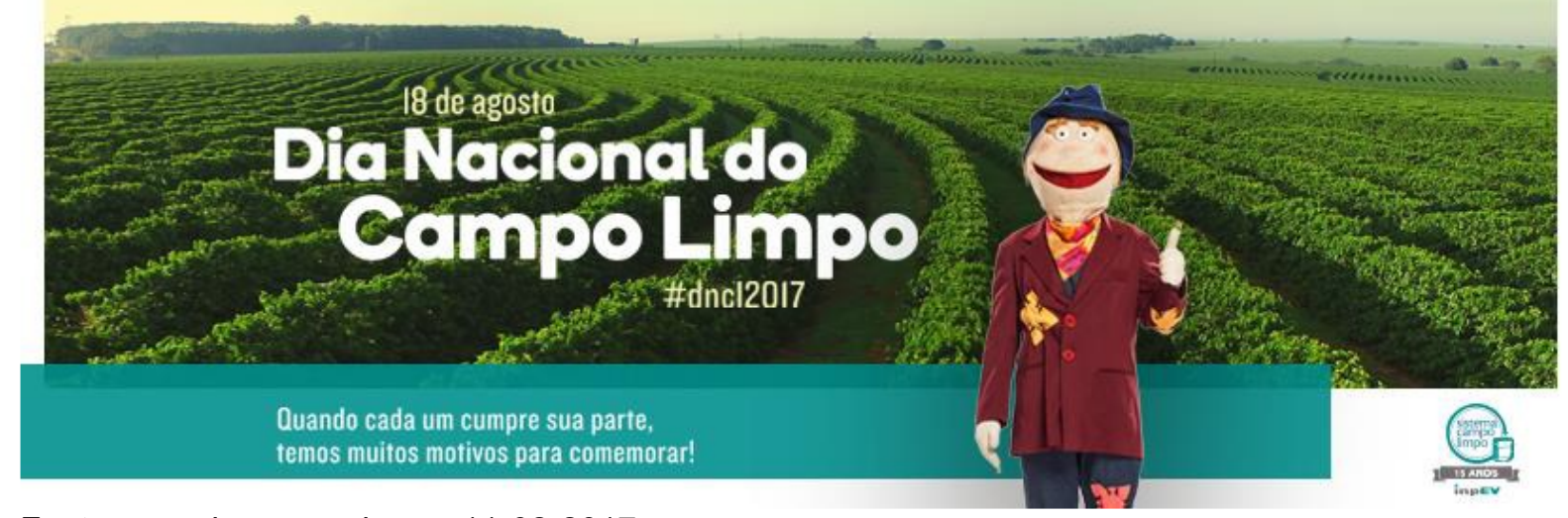

Fonte: www.inpev.org.br em 11-02-2017

O slogan "Quando cada um cumpre sua parte, temos muito motivos para comemorar" é extremamente falacioso, visto que o alto índice de uso de agrotóxicos vai à contramão da sustentabilidade. O simples fato de recolher parte das embalagens contaminadas para reciclagem não significa que o instituto prime por uma postura próambiental, visto que, sendo financiado pela indústria agroquímica, estimula a produção agrícola de base conservadora e tóxica e o modelo dominante do agronegócio. 


\section{CONSIDERAÇÕES FINAIS}

Ao analisar o conteúdo do site do Inpev, percebe-se que a ênfase dos textos recai sobre embalagem em detrimento à substância que a embalagem contém, ou seja, o agrotóxico. Destaca-se o plástico da embalagem e raramente se menciona o biocida, produto fatal e tóxico, que é transportado.

A indústria agroquímica movimenta altos investimentos no setor e produz, para tal, um discurso que visa gerar consenso em torno da produtividade e da sustentabilidade, associando seus produtos à imagem da solução moderna para a agricultura. Desta forma, percebemos que instituições com interesses mercadológicos quando responsáveis por comunicar os riscos relacionados a seus produtos, não desempenham de forma prudente este papel, deixando os usuários dos produtos agrotóxicos ainda mais vulneráveis.

Nesse processo de responsabilidade compartilhada, que cabe a indústria produtora amenizar os danos causados ao meio ambiente, entende-se como prioridade o papel do Estado no controle e na fiscalização da logística reversa. Situação que no contexto brasileiro parece ser bastante frágil visto que o investimento de recursos públicos para controles ambientais, principalmente em choque com interesses empresariais, está cada vez mais escasso. A CR deve ser dialógica, ofertando aos agentes afetados pelo risco todas as informações necessárias para que as atitudes mais adequadas sejam tomadas, inclusive no tocante às prevenções dos riscos. Dentre as estratégias de comunicação do Inpev, evidenciamos que, embora a legislação vigente determine a obrigatoriedade do uso do termo agrotóxico, este lança mão de deslocamentos semânticos ao usar o termo defensivo agrícola para suavizar os riscos inerentes ao produto agroquímico.

Resta, então, ao agricultor, ponta da cadeia da logística reversa que ocupa uma posição menos privilegiada neste ciclo, a quem é destinado a imagens coloridas e espantalhos sorridentes, despertar do torpor midiático que valoriza a produtividade no campo e pouco questiona sobre a sustentabilidade, se perguntar como pode um produto tão tóxico ser defensivo? Defende quem? Se o produto não defende nem a saúde do trabalhador e nem o meio ambiente pouca associação pode ser estabelecida entre o produto e o termo defensivo, salvo a defensiva mercadológica do lucro destas corporações.

Sendo assim, onde se encontra a confiança neste processo? Ao lançar campanhas de cunho tão vital para a sociedade, o Inpev, utilizando figuras de linguagem para dissimular o peso conotativo do termo agrotóxico, pode comprometer a saúde coletiva e todo o ecossistema. Como a confiança é um dos pressupostos da comunicação dos riscos, para que a mensagem seja aceita pelo público, uma CR deve envolver responsabilidade, solidariedade e alteridade, indicando que agentes impessoais ou "desumanizados" não desenvolverão bons papéis dentro da CR. Neste sentido, questiona-se o empenho do Inpev em atingir todo o público que é afetado pelo risco da lida com estas embalagens, visto que a comunicação é focalizada nos meios digitais, fator limitante de comunicação no meio rural.

Esta campanha do Inpev pode ser interpretada da seguinte forma: sinta-se bem ao devolver a embalagem porque nossa empresa cuida de você, ajuda você a produzir mais 
e cuida do meio ambiente, continue comprando nosso produto, devolvendo a embalagem e estamos todos quites com o sistema. No entanto, dissimuladamente diz: não pense sobre nossos lucros nem sobre a sua saúde e de sua família, não existe outro meio de produzir alimentos, você está preso a esta cadeia.

O uso de agrotóxicos, mais que uma escolha individual, é uma imposição estrutural, e desta forma, o Inpev não realiza debates mais profundos acerca do uso dos produtos agrotóxicos em seu site. Desassocia o grande número de embalagens retornadas do alto, ou até exagerado, consumo do produto nas lavouras, velando, assim, informações que podem transformar as práticas agrícolas em processos sustentáveis, como a agroecologia, em favor do grande conglomerado industrial que o sustenta.

\section{REFERÊNCIAS}

Araujo $\mathrm{A} \mathrm{J}$ et al. Exposição múltipla a agrotóxicos e efeitos à saúde: estudo transversal em amostra de 102 trabalhadores rurais, Nova Friburgo, RJ. Ciência \& Saúde Coletiva. 2007;12(1):115-130.

Bardin L. Análise de conteúdo. Lisboa: Edições 70; 1977.

Beck U. Sociedade de risco: rumo a uma nova modernidade. São Paulo: Ed. 34; 2010.

Bombardi L M. Geografia do uso de agrotóxicos no Brasil e conexões com a União Europeia. São Paulo: FFLCH - USP; 2017.

Carneiro F F (Org.) Dossiê ABRASCO: um alerta sobre os impactos dos agrotóxicos na saúde. Rio de Janeiro: EPSJV; São Paulo: Expressão Popular; 2015.

Covello V T. Communicating risk information: a guide to environmental communication in crisis and noncrisis situations. In: Kolluru R V (ed.). Environmental strategies handbook: a guide to effective policies and practices. New York; 1993

Di Giulio G M et al. Experiências brasileiras e o debate sobre comunicação e governança do risco em áreas contaminadas por chumbo. Ciênc. saúde coletiva. 2012 fev. ;17(2):337-349.

Ervilha I C. Relatório: Vigilância em saúde de populações expostas a agrotóxicos no estado de Minas Gerais. Coordenação Geral de Vigilância em Saúde Ambiental (CGVAM), Departamento de Vigilância em Saúde Ambiental e Saúde do Trabalhador (SVS/MS); 2014.

Fischhoff B. Risk perception and communication unplugged: twenty years of process. Risk Anal; 1995: 137-145. 
Furnival A C, Pinheiro S M, Junior J C O. A comunicação e compreensão da informação sobre riscos. DataGramaZero: Revista de Ciência da Informação. 2004; $5(2)$.

Gomes M A F, Monticelli R R. Panorama da contaminação ambiental por agrotóxicos e nitrato de origem agrícola no Brasil: cenário 1992/2011. Jaguariúna, SP: Embrapa Meio Ambiente; 2014.

Guivan J S. O legado de Ulrich Beck. Ambiente \& Sociedade. 2016 jan./mar.; 19(1): 229-240.

INPEV. Relatório de sustentabilidade. São Paulo; 2016. Disponível em: https://www.inpev.org.br/Sistemas/Saiba-Mais/Relatorio/inpEV_RS2016.pdf>

Jesus S. Comunicação do risco: o que dizer, quando dizer. Instituto Politécnico de Lisboa. Universidade de Aveiro; 2016.

Lofstedt R. Risk Management in Post-Trust Societies. Londres: Ed. Routledge; 2012.

Neves F R M. Efeito dos agrotóxicos e seus metabólitos em células sanguíneas. [Dissertação (Mestrado em Hemoterapia e Medicina Transfusional)] Ribeirão Preto: Faculdade de Medicina de Ribeirão Preto, Universidade de São Paulo; 2017. [Acesso em: 2017 nov. 02]. Disponível em: <http://www.teses.usp.br/teses/ disponiveis/17/17155/tde-07062017-152230/>.

Oliveira V C. Indústria cultural e meio rural. Revista mediação. 2012 jan./jun.; 14 (14).

Peirce C S. Semiótica. São Paulo: Perspectiva; 1977.

Santos I M F A. Comunicação e governança de risco. Construção de um modelo de capacitação social. [Tese (Doutorado em Ambiente e Sustentabilidade)]. Lisboa:

Faculdade de Ciências e Tecnologia, Universidade Nova de Lisboa; 2016.

Soriano É. A identificação e análise da comunicação do risco de desastres naturais em municípios do estado de São Paulo. Centro Nacional de Monitoramento e Alertas de Desastres Naturais. CEMADEN, Universidade Federal de São Carlos- UFSCar, 2016. Revista da Associação Nacional de Pós-graduação e Pesquisa em Geografia (Anpege). 2016 jul./dez.; 12 (19): 390-408.

Artigo recebido em: 19/11/2018

Artigo aprovado em: 17/06/2019

Artigo publicado em: 10/07/2019 